\title{
El Proyecto Lingüístico de Centro y el Currículo Integrado de Lenguas: dos instrumentos pedagógicos indispensables en la educación bilingüe
}

\author{
Víctor CANTERO GARCÍA \\ Departamento de Filología y Traducción \\ Universidad Pablo Olavide, Sevilla \\ cantero91@hotmail.com \\ Gunn AARLI \\ Doctoranda de la Universidad de Cádiz
}

Recibido: octubre 2011

Aceptado: marzo 2012

\section{RESUMEN}

En la presente colaboración tratamos de resaltar la importancia que adquiere el desarrollo de la competencia lingüística de nuestros alumnos de la ESO, a través de dos instrumentos pedagógicos y didácticos complementarios: el Proyecto Lingüístico de Centro y el "currículo integrado". En este artículo ofrecemos al lector un conjunto de argumentaciones lingüísticas y metodológicas, las cuales le ayudarán, sin duda a comprender que el "currículo integrado" adquiere su pleno sentido al ser considerado como parte del eje vertebrador en el que se integran todos los aprendizajes efectuados a través de la L2.

Nuestras afirmaciones son completadas con una ejemplificación de secuenciación de contenidos para un área no lingüística del currículo escolar.

Palabras clave: Proyecto Lingüístico de Centro, "currículo integrado", enseñanza bilingüe.

The Language Project of the Centre and the integrated curriculum: two essential teaching tools in bilingual education

\begin{abstract}
Through this collaboration, we try to emphasize the importance of development of our students of ESO language skills through two complementary tools pedagogical and didactical namely: language project of the centre and the integrated curriculum.

In this paper, we propose to drive a set of linguistic and methodological arguments which will no doubt help understand the integrated curriculum makes sense and must be considered as the backbone of all courses and apprenticeships in L2. We have add-ins to amplify the sequences for students enrolled in non-linguistic area.
\end{abstract}

Key words: language project, integrated curriculum, language skills, bilingual education 


\section{Le Projet Linguistique d'établissement et le curriculum intégré : deux outils pédagogiques indispensables à l'enseignement bilingue.}

\section{RÉSUMÉ}

Grâce á cette collaboration, nous essayons de souligner l'importance du développement des compétences linguistiques de nos étudiants de ESO, et ce à travers deux outils complémentaires à la fois pédagogiques et didactiques à savoir : le projet linguistique d'établissement et le curriculum intégré.

Dans cet article, nous proposons au lecteur un ensemble d'argumentations linguistiques et méthodologiques qui aideront sans doute à comprendre que le cursus intégré prend tout son sens et doit être considéré comme l'épine dorsale de tous les cours et apprentissages dispensés en L2. Nos propositions sont complétées par des exemples de séquences de contenus destinées aux élèves inscrits dans les DNLs.

Mots-clé : projet linguistique, curriculum intégré, compétences linguistiques, l'éducation bilingue.

SUMARIO: 1. Introducción. 2. ¿En qué premisas pedagógicas y en qué fundamentos didácticos de se basa el PLC? 3. ¿Por qué el Currículo Integrado de Lenguas es una parte esencial del PLC? 4. ¿En qué medida el «lenguaje integrado» conforma el soporte teórico del «currículo integrado». 5. De la teoría a la práctica: una secuenciación de contenidos para el área de Matemáticas en $1^{\circ}$ de ESO bilingüe. 6. Consideraciones finales. 7. Referencias bibliográficas.

\section{INTRODUCCIÓN}

Tras la entrada en vigor del Plan de Fomento del Plurilingüismo en Andalucía, (Acuerdo de Consejo de Gobierno de 23.3.2005, BOJA de 5.4.2005) en el curso 2005/2006 se efectuó en esta Comunidad Autónoma la primera convocatoria para la selección de Centros Bilingües. Pues bien, desde dicho curso este articulista sigue vinculado a las tareas docentes propias de la educación bilingüe, bien como Coordinador de Sección Bilingüe en IES (español-inglés) bien como profesor de Área Lingüística (AL) en dicha Sección. Desde los inicios de esta experiencia educativa somos muchos los profesores que hemos reclamado la correcta ubicación de la metodología bilingüe en el marco general del Proyecto Lingüístico de Centro (PLC). A tal fin hemos venido insistiendo en la imperiosa necesidad de contar con un lugar específico dentro de la propuesta general, que para la mejora de la competencia lingüística de nuestros alumnos, se realiza desde los IES. Y es justo en este momento, es decir, cuando la iniciativa de dotar a los IES de un PLC toma cuerpo, cuando nuestra reivindicación adquiere todo su sentido. Esta es la razón que justifica la presente colaboración, a saber: aportar al lector los argumentos pedagógicos y didácticos que evidencian que el «currículo integrado», como recurso metodológico propio de la educación bilingüe, tiene una importancia clara y ocupa un lugar destacado entre las iniciativas en pro de una enseñanza 
coordinada de todas las lenguas del currículum que se enseñan en la ESO. A quienes dedicamos tiempo y esfuerzo a estas cuestiones nos parece importante que se cuente con una explicitación de las razones, en base a las cuales es posible una armoniosa convivencia entre las directrices pedagógicas emanadas del PLC y las propuestas metodológicas propias de la educación bilingüe.

$\mathrm{Y}$ es al calor de este debate encaminado a evitar el divorcio entre los esfuerzos por incrementar las habilidades lingüísticas de nuestros alumnos/as - que se derivan de la aplicación del PLC- y el afán por lograr lo mismo desde la metodología bilingüe, aplicada en algunos IES andaluces, es donde surge la presente aportación. Dedicamos la primera parte de la misma a exponer las razones que justifican la necesidad de establecer un nuevo marco de actuación didáctica unificado para afrontar las nuevas situaciones de aprendizaje, tanto desde la L1 como desde la L2. Nos referimos a un nuevo modelo de enseñanza de las lenguas en el cual, tal como nos señala Fernando Trujillo Sanz, (2007 p. 71) "los pilares fundamentales son la enseñanza por competencias y tareas; el currículo integrado, el aprendizaje cooperativo y el uso de las TIC en el aula." Un nuevo enfoque que hunde sus raíces en el "Marco Común Europeo de Referencia para las Lenguas: aprendizaje, enseñanza y evaluación", (Consejo de Europa, 2001). Este nuevo referente pueda denominarse Proyecto Lingüístico de Centro (PLC), dentro del cual tratamos de ubicar la propuesta de enseñanza bilingüe, que a partir de la aplicación de la metodología CLIL se pretende poner en práctica en las Secciones Bilingües de nuestros IES. Por tanto, en esta primera parte tratamos de contextualizar adecuadamente el modelo de educación bilingüe y el desarrollo del «curriculo integrado» en el entramado global del PLC. Un encuadre que se hace preciso, toda vez que tal como sostienen A. Gómez Vidal y D. Arcos $(2007$, p. 1) "en el PLC deben tener cabida las prácticas habituales de la mayoría de los docentes en lo referente a la mejora lingüística de nuestros estudiantes. Dichas prácticas se presentan ahora como un corpus estructurado que aporta estrategias tanto para la implementación de la enseñanza de las lenguas, como para su posterior desarrollo y evolución. Por ello el PLC es un plan integral que afecta a todas las áreas del currículo y a todos los niveles de la ESO."

En la segunda parte de nuestra exposición pretendemos aportar al lector los argumentos precisos que le hagan comprender hasta qué punto el Currículo Integrado de las Lenguas, que es el recurso pedagógico esencial de la enseñanza bilingüe, no entra en ningún momento en contradicción con las propuestas metodológicas que sustentan al PLC. Al contrario, la aplicación del «currículo integrado» en los IES bilingües da pleno sentido al desarrollo del PLC, el cual se constituye como un instrumento aglutinador de todos los aprendizajes de lenguas en el Centro escolar. Un aprendizaje basado en el uso de cada lengua y en la puesta en valor de su capacidad comunicativa. Este nivel de complementariedad de ambos elementos es destacado por Mercé Bernaus (2004, p. 3), toda vez que "si el profesorado en general tiene una actitud positiva hacia las lenguas presentes en el 
currículo, puede ayudar a los alumnos a reforzar el concepto de identidad que va muy ligado a la competencia lingüística, a la predisposición hacia el uso de la lengua." Y esta lógica complementariedad entre lo que entendemos por modelo bilingüe de enseñanza de lenguas y el PCL es resaltada por otros estudiosos del fenómeno lingüístico, para quienes existe una relación estrecha entre el nivel de competencia que un hablante adquiere en el dominio de su lengua materna (LM) y el influjo que en dicho aprendizaje tienen las actividades lingüísticas generales del hablante en relación con la lengua y la cultura propias de la L2. Tan estrecha es esta relación que, como precisa C. Baker (1992, p. 44) "es posible que exista un influjo recíproco. Tanto las actividades como los logros en el dominio de la L2 pueden ser los dos la causa y el efecto el uno del otro. En una relación cíclica, en una relación espiral el uno influye en el otro, en una relación que sube y baja, asciende y desciende." Complementariedad que es, a su vez, subrayada por J. Cummins (1979, p. 234) cuando al explicar su denominada Hipótesis de la Interdependencia, sostiene que "el nivel de competencia en L2 que un niño bilingüe adquiere depende, en parte del tipo de competencia que dicho niño ha desarrollado en L1, en el momento en el que empieza su exposición intensa a la L2." Y ello sin olvidar la importancia que la interacción verbal tiene en las aulas bilingües, importancia que es subrayada por Mijail Bajtin, (1929), al afirmar que: "la verdadera substancia del lenguaje no está constituida por un sistema abstracto de formas lingüísticas, sino por el fenómeno social de la interacción verbal, realizada a través de la enunciación y de las enunciaciones".

Una vez despejadas todas las dudas en relación con el oportuno maridaje entre la enseñanza de las lenguas del Centro y el modelo bilingüe, basado en la metodología CLIL y el enfoque comunicativo propio de la enseñanza por tareas, pasamos en un tercer momento a buscar las raíces de lo que a nuestro entender es el soporte primario de la educación bilingüe, a saber: «el currículo integrado». En cierto modo, en esta sección pretendemos enfatizar la especificidad didáctica y metodológica del elemento sustancial de la educación bilingüe. De un lado, nos parece incuestionable el hecho de que el PLC debe ser gestionado desde una perspectiva plurilingüe, o lo que es lo mismo desde una óptica en la que cada lengua no sea programada de forma independiente del resto, es decir que tal como señalan $M^{a}$ Pilar Sagasti Arresti y otros (2000, p. 1) "la puesta en marcha del PLC supone provocar una interrelación entre todas las lenguas que se usan y que se imparten en el Centro escolar, todo ello con el fin de provocar un proceso de cambio desde una gestión monolingüe a otra plurilingüe del PLC". Mientras que de otro, entendemos que es necesario aportar al lector lo que a nuestro juicio pueden ser los antecedentes del «currículo integrado», que a la sazón no son otros que el «lenguaje integrado» o «whole language», tal como lo denomina la psicolingüística. Nos referimos a toda una filosofía del lenguaje que surge en el mundo anglosajón y que propugna un principio incontestable, a saber: "que cuando el lenguaje es un todo relevante y funcional, el que aprende tiene metas reales para 
usarlo", tal como sostiene Y. M. Goodman (1990, p. 225). Parece claro que los elementos primarios de los que se nutre el «lenguaje integrado», como movimiento de enseñanza-aprendizaje de lenguas innovador y alternativo, constituyen el cimiento sobre el que se asienta el modelo de educación bilingüe centrado en la aplicación del Currículo Integrado de las Lenguas. Hacia esta dirección apuntan opiniones como la de B. S. Bergeron (1990, p. 319), quien define el «leguaje integrado» como "un concepto que incluye tanto una filosofía del lenguaje como una aproximación instruccional enmarcada y apoyada por esa filosofía. Este concepto incluye el uso de la literatura, de la escritura real en el contexto de experiencias significativas, funcionales y de cooperación, con el fin de desarrollar en los estudiantes la motivación y el interés durante el proceso de aprendizaje". A partir de definiciones como la anterior resulta más sencillo comprender los puentes que existen entre este movimiento pedagógico y lo que nosotros entendemos por «currículo integrado», pues en ambos casos se parte del convencimiento de que el procedimiento más adecuado para fomentar las destrezas lingüísticas de los alumnos de la ESO pasa por admitir que las lenguas se aprenden con su uso. Es decir que es con la práctica en el entorno social del aprendiz donde se produce dicho aprendizaje. Un aprendizaje que se desarrolla a través de un proceso de construcción de significados, los cuales afloran con más facilidad si el estudiante mantiene unas fluidas relaciones con las personas que configuran su entorno.

Y para compensar la desatención que, a nuestro juicio, se le presta al «currículo integrado» en la elaboración del PLC, aportamos, en un cuarto y último apartado, nuestro granito de arena. Entendiendo que desde la Sección Bilingüe de nuestro IES tenemos como objetivo primario lograr un aumento de las destrezas lingüísticas de nuestros alumnos tanto en L1 como en L2, por medio del desarrollo de sus competencias interlingüísticas, aportamos al lector una serie de ejemplos de cómo secuenciar los contenidos integrados de un área no lingüística de la ESO implicada en la enseñanza bilingüe de la correspondiente Sección. Nos referimos a un conjunto de ejemplificaciones didácticas de lo que entendemos por «currículo integrado», las cuales pretenden demostrar que para que el PLC sea, tal como señala J. A. González Riaño, (1988, p. 112) “el instrumento a través del cual cada escuela elabore su propia estrategia de acción normalizadota a partir de las relaciones sociolingüísticas y socioculturales concretas del alumnado", se hace preciso admitir, como sostiene Uri Ruiz Bikandi, (1997, p. 16) que existen "diferentes elementos que deben incorporarse al PLC, y por ende al PC y al PCC, entre ellos la situación de los alumnos en relación con su competencia en la primera y segunda lengua, así como en relación con las demás lenguas de uso del Centro". Y entre dichos elementos, destaca de manera singular el «currículo integrado», el cual debe animar al profesorado a replantearse las representaciones sociales de la enseñanza de las lenguas, pues la adquisición de las lenguas no es un simple saber escolar, sino que es una competencia humana, es decir; que todos los hablantes disponemos de representaciones sobre la manera en que las lenguas han 
de ser aprendidas, al margen de que el aprendiz acuda o no a la escuela. Por ello, corresponde al profesorado de los IES bilingües elaborar su propio modelo de «currículo integrado» de las lenguas y las áreas no lingüísticas. Una elaboración en la que no se puede pasar por alto el hecho de que en la educación bilingüe ha de primar la adquisición de capacidades lingüísticas por parte de los alumnos, el desarrollo de sus habilidades discursivas y el incremento de sus niveles de reflexión sobre las lenguas utilizadas en sus actos de comunicación. Se trata de un bilingüismo que pone su acento en las actividades orales relacionadas con el aprendizaje de las lenguas, dando menor importancia a los contenidos gramaticales. En suma, nos referimos a una propuesta de enseñanza de lenguas en la que "se produce al integración de procedimientos, destrezas y funciones comunicativas, de cara a rentabilizar la enseñanza de la $\mathrm{L} 2$. Se trata de una propuesta que procura que lo que se aprende sea rápidamente rentabilizado, que enfatiza los modos espontáneos de adquisición de las lenguas y que considera primordial el desarrollo de la competencia de «aprender a aprender», gracias a la cual se consigue un aprendizaje de lenguas más reflexivo y autónomo". Consejería de Educación, (2005:28)

En un último momento dedicamos el espacio y atención requeridos a las conclusiones. En la exposición de las mismas ponemos de manifiesto que el binomio formado por el PLC y el Currículo Integrado de las Lenguas se asienta como una realidad necesaria en los IES bilingües andaluces. Esto implica que todas las propuestas encaminadas a potenciar las competencias lingüísticas de nuestros alumnos deben ser llevadas al aula tanto por los profesores de las ALs como los de las ANLs. En suma, venimos a concluir que la educación bilingüe y la metodología CLIL sí cuentan con un lugar destacado en el PLC y conforman con el mismo una realidad inseparable.

\section{2. ¿EN QUÉ PREMISAS PEDAGÓGICAS Y EN QUÉ FUNDAMENTOS DIDÁCTICOS SE BASA EL PLC?}

Dado que el objeto central de nuestra colaboración consiste en lograr la correcta ubicación del «currículo integrado» en el marco general del PLC de los IES andaluces, parece lógico que comencemos por aportar al lector aquellas razones que, a nuestro juicio, reclaman la existencia del citado PLC en los Centros escolares. Centros que en pleno siglo XXI acogen en sus aulas a alumnos que cuentan con distintos niveles de competencia lingüística en relación con las lenguas que se hablan y que se estudian en la escuela. Y precisamente, tal como señala Fernando Trujillo Sanz, (2007, ibídem, p. 72) el primer motivo por el que se hace necesario contar con el PLC viene dado por el hecho "de que los IES andaluces cuentan con alumnos que poseen una gran diversidad cultural y lingüística desde sus situaciones de origen, se trata de alumnos que tienen el castellano como L1, ubicados en comunidades monolingües que pretenden el dominio de la L2 o se trata de estudiantes, hijos o hijas de familias de origen extranjero, para los cuales la 
lengua de la escuela puede ser una L2.” De aquí se deduce que en nuestros IES existen alumnos con una gran diversidad de intereses, necesidades y actitudes hacia las lenguas, sus aprendizajes y sus hablantes. Y para dar respuesta a tal diversidad se necesita un PLC en el que se delimiten las distintas didácticas de las lenguas, bien diferenciadas en función de cada situación, a saber: didáctica de la LM, didáctica de las lenguas extrajeras (LE) y didáctica de la segunda lengua. Y es justo la necesidad de dar respuesta a las demandas lingüísticas de un alumnado tan heterogéneo la que reafirma la importancia del PLC como un nuevo marco de actuación didáctica, en el que uno de sus pilares esenciales es el «currículo integrado».

Una segunda razón, no menos importante que la anterior, emana del hecho incuestionable de que la enseñanza-aprendizaje de lenguas ha experimentado en los últimos años un cambio radical de enfoque. Ya ha quedado atrás el afán gramaticalizador del aprendizaje de las lenguas, pues ahora el epicentro de dicho aprendizaje consiste en el dominio de las mismas por medio de su uso. Y este cambio de enfoque obliga a todo el profesorado del Centro, no solo a los docentes especialistas de las AL, a la elaboración de un PLC en el que se expliciten los objetivos a lograr por cada IES en el ámbito del aprendizaje de lenguas. De acuerdo con ello, el PLC surge del compromiso total de todo el profesorado del Centro por delimitar un nuevo modelo: integrador, global y flexible para la enseñanza-aprendizaje de las lenguas. Modelo que deja a un lado el interés por inculcar al alumnado el sistema lingüístico y pone el acento en las funciones sociales de la lengua. En suma, hablamos de un nuevo referente con el que, en palabras de M. Cejas Martínez, (2005, p. 19) "se pretende que los alumnos sean hábiles para comunicarse de forma eficaz en distintas lenguas. Un enfoque integrador que busca vehicular la educación por competencias y tareas como parte esencial del PLC". De aquí que todos los esfuerzos del PLC se encaminen hacia la mejora de la competencia comunicativa de los alumnos a través de la adquisición de una competencia lingüística cada vez más acorde con cada uno de los actos comunicativos. Hablamos de conseguir que los alumnos sean competentes como personas, es decir; que sepan utilizar la lengua para resolver problemas de comunicación en la vida real. Un cambio de enfoque que es preciso, pues de no haberse producido, tal como sostiene J. M Vez Jeremías (2008, p. 18) "la lenguas seguirían siendo entendidas como asignaturas, las cuales quedan apartadas del proceso de apropiación cultural que garantiza la competencia comunicativa en cualquier lengua."

Sin embargo, este cambio de orientación en la enseñanza de las lenguas no sería eficaz de no ir acompañado de lo que hoy entendemos como enseñanza "por tareas", que no es otra cosa que la actividad y el esfuerzo que el alumno realiza para aprender una lengua de forma significativa. Un aprendizaje significativo que se concreta en la ejecución de una serie de "tareas", todas ellas vinculadas a la resolución de problemas concretos de su vida diaria. Nos referimos a un enfoque 
operativo del aprendizaje de lenguas, aprendizaje que se relaciona con la realización de trabajos específicos, cuya evaluación positiva estará en función de los objetivos logrados en cada caso. Este modelo de aprendizaje potencia en el alumno la reflexión sobre el lenguaje, al mismo tiempo que le facilita la adquisición de la competencia lingüística. Justo todo lo contrario a lo que en la actualidad sigue siendo el denominador común en los procesos de enseñanzaaprendizaje de la L1. Unos procesos que en que palabras de E. Galera Noguera y J. L. Molina, (2000, p. 148) "siguen estando orientados en la mayoría de los casos a la realización de una serie de actividades - se refiere a la clase de Lengua Española como L1 - poco motivadores, encaminados a conseguir unos objetivos formales, que a penas tienen relación con el uso de la lengua, olvidando que el aprendizaje de una lengua es anterior al conocimiento de sus reglas gramaticales." Pero si poderosa es esta razón a favor del PLC, no lo es menos el hecho de que por medio de la aplicación del mismo ha se estimularse la conciencia lingüística de los alumnos. Una conciencia que es necesaria para propiciar en ellos la reflexión sobre el lenguaje como procedimiento para mejorar su aprendizaje. Aludimos a un interés y un afán por aprender lenguas que, en palabras de N. Spada, (1997, p. 73) "se concreta en cualquier esfuerzo que atraiga la atención de los estudiantes hacia la lengua, tanto de manera explícita como implícita". Conciencia lingüística que es imprescindible, pues tal como señala Mijail Bajtin (1984: 284) "para hablar necesitamos ser conscientes de que nos servimos siempre de los géneros del discurso, es decir, que todos nuestros enunciados disponen de formas tipo, relativamente estables".

Un tercer motivo que justifica la existencia del PLC es la necesidad de contar con un documento pedagógico en el que se recojan las decisiones que adopte el profesorado en lo que afecta a la educación lingüística de los alumnos. Unas decisiones, que en opinión de Mercé Bernaus, (2004, ibídem, p. 4) "han de ser compartidas por todos los docentes dentro de un proyecto global en el que participe todo el Claustro de profesores, de manera que el tratamiento lingüístico y cultural de las lenguas objeto de estudio no sea exclusivo de las materias relacionadas con la enseñanza-aprendizaje de las lenguas". Unas decisiones, que cuando menos han de ser tomas en relación con asuntos tan importantes como: la distribución de las lenguas en la escuela y en el currículo, las decisiones sobre la LM del estudiante y sobre las lenguas ambientales, todo lo que afecta a la evaluación de la competencia lingüística de los alumnos, así como las propuestas metodológicas generales en relación con la enseñanza de las lenguas. Y para que estas decisiones sean firmes y se lleven a la práctica es necesario que los docentes que respaldan el PLC estén convencidos de que sus acuerdos en relación con el uso de las lenguas en los diferentes ámbitos del Centro son de vital importancia, toda vez, que tal como señala J. A. González Riaño (1998, ibídem, p. 114) "la escuela juega un papel esencial como compensadora de desigualdades, a la vez que como agente de eliminación de prejuicios. El desigual uso de las funciones sociales de las lenguas 
en contacto exige que la escuela ofrezca situaciones de comunicación ricas y variadas en la lengua minoritaria". Un convencimiento que se transforma en compromiso en el mismo momento en el que el profesorado acepta el reto de "definir qué tipo de propuestas lleva adelante para dar respuesta a la diversidad lingüística presente en los Centros. Unas propuestas que para ser congruentes con dicha diversidad deben ser globales e incluir tanto los nuevos retos que plante la comunicación en LM, como la incorporación de una o varias lenguas nuevas, genéricamente denominadas como L2, al currículo escolar", tal como afirma D. Ojeda Álvarez, (2008, p. 77)

No obstante, y pese a lo poderosos que son los argumentos ya expuestos, el que a continuación exponemos no lo es menos. Nos referimos al influjo contrastado que existe entre el desarrollo de la competencia lingüística de los alumnos y su éxito y promoción en el ámbito académico. A estas alturas parece claro que el éxito académico cosechado por los alumnos de la ESO depende en gran medida de su grado de desarrollo de una serie de habilidades lingüístico-cognitivas. De aquí que resulte lógico que la iniciativa de poner en marcha los PLCs en los IES andaluces surja tras comprobar que el Informe de Resultados de las Pruebas de Diagnóstico correspondiente al curso 2006/2007, venía a concluir que "tanto en el alumnado de la E. Primaria, como entre el de la ESO, los hábitos de lectura no se encuentran demasiado extendidos. Para la mayoría de los tipos de lectura (...) gran parte del alumnado evaluado en la muestra afirma no practicar la lectura nunca o casi nunca fuera del marco escolar." Consejería de Educación, (2007, p. 35). La detección de estas carencias en los distintos ámbitos de la competencia lingüística, bien sea en el uso oral o escrito de la lengua se viene comprobando en Andalucía curso tras curso, pues los resultados de estas Pruebas manifiestan que el alumnado no posee en el grado deseado las habilidades y estrategias lingüísticas que precisa para desenvolverse con soltura en su vida cotidiana. Esta realidad fue la que hizo saltar las alarmas y para atajarla se hacía preciso que los distintos IES elaborasen PLCs en los que estas deficiencias se subsanasen. Hablamos de unos documentos pedagógicos en cuya articulación ha de recogerse el tratamiento de todas las lenguas, tanto la L1 como la L2, estableciendo como objetivo prioritario en el caso de la segunda "profundizar en las destrezas discursivas de los alumnos adquiridas anteriormente, enriquecer su repertorio y ampliar los ámbitos en los que tienen lugar. Y dentro de dichos ámbitos cabe destacar: el de las relaciones sociales y las prácticas sociales habituales y el académico, ampliando aquellos contenidos relacionados con la materia." CEP de Jaén (2011, p. 1). Conscientes, por tanto, de lo importante que es el hecho de que cada PLC refleje las decisiones del profesorado en este ámbito, parece claro que es preciso abundar en los motivos que lo justifican. Damos por sentado que el principio de integración curricular ha de presidir la elaboración del PLC. Una integración que se convierte ya en una práctica habitual en la planificación educativa de los Centros bilingües. 


\section{3. ¿POR QUÉ EL CURRICULO INTEGRADO DE LENGUAS ES UNA PARTE ESENCIAL DEL PLC?}

Para dar una respuesta motivada a esta cuestión hemos de comenzar por admitir una premisa básica, a saber: que la lengua es un elemento esencial de la identidad de cada individuo, sin la lengua no hay persona individual e irrepetible. Tal como sostiene Amin Maalouf, (1999, p. 41), "de todas las pertenencias que atesoramos, la lengua es casi siempre de las más determinantes". En la lengua encontramos pertenencia, cultura y conocimiento colectivo, al mismo tiempo que espacio personal, intimidad y recogimiento. Las lenguas son de todos y de cada uno de nosotros. De acuerdo con esta forma de concebir la lengua, los objetivos de todo PLC han de dar respuesta a las necesidades lingüísticas y comunicativas de los alumnos como usuarios de la lengua, es decir; como seres vivos que necesitan de la lengua para relacionarse mejor, relegando a un segundo lugar la lengua entendida como paradigma o modelo formal. De aquí se desprende el hecho de que desde el PLC la escuela debe atender a un alumnado multilingüe y heterogéneo, al cual debe preparar para que domine de manera efectiva tanto la lengua de instrucción y de comunicación social en Andalucía, a saber: el castellano como L1, como aquellas otras L2 presentes en el currículo escolar. Y cuando hablamos de otras L2 nos referimos a aquellas LE cuyo estudio se impulsa desde la educación bilingüe y que en el caso andaluz han pasado a cobrar mayor relevancia tras la entrada en vigor en 2005 del Plan de Fomento del Plurilingüismo. Una iniciativa en materia de política lingüística que, en opinión de F. Ramos (2007, p. 143) "ha contribuido a la mejora del aprendizaje de idiomas en Andalucía mediante la creación de programas bilingües, en los que el francés, el inglés y el alemán, además del español, son usados como lenguas vehiculares de instrucción y de comunicación en las aulas. Esto permite que los alumnos cuenten con una mayor utilización de los idiomas, así como de su uso en situaciones reales y con ello lograr una mejor y mayor capacitación lingüística y académica del estudiante.”

Precisamente el acierto de esta iniciativa descansa en la consideración del «currículo integrado» como el instrumento idóneo que, enmarcado en el PLC, dote de mayor coherencia al estudio de las lenguas, acabando con la tradicional fragmentación del mismo. Nos referimos al «currículo integrado» como un recurso pedagógico que conceda a los IES la posibilidad de que sus alumnos adquieran al mismo tiempo los contenidos curriculares y las lenguas, lo que refuerza la importancia de que dicho currículo forme parte inseparable del PLC, toda vez que, tal como nos precisa I. Gómez Alemany (2000, p. 4), "el lenguaje forma parte del currículo: como sistema de comunicación en el aula y en la escuela, como medio de aprendizaje - para aprender los conocimientos de las diferentes áreas - y como objeto de aprendizaje." Y era justo esa fragmentación en la enseñanza de las lenguas la que, hasta el presente, acentuaba la enseñanza de la LM, el castellano, como una materia que no tenía nada que ver con el resto de las áreas del currículo, lo mismo que las demás ANLs parecían haberse olvidado de que el mecanismo 
esencial para la enseñanza-aprendizaje de sus contenidos pasa por el domino de la L1. Esta situación toca a su fin tras el asentamiento en los IES del Currículo Integrado de Lenguas, alma mater de la educación bilingüe. El desarrollo del mismo en los IES bilingües andaluces contribuye a afianzar un aprendizaje significativo de todos los demás contenidos de las ANLs. Por ello, la presencia del «curriculo integrado» se hace indispensable en los Centros, toda vez que el trasvase de las lenguas a los contenidos y viceversa es una realidad que afecta a todas las materias curriculares, de tal modo que, tal como sostiene G. Spanos, (1989, p. 228) gracias a este trasvase "inyectamos el contenido significativo y relevante de las áreas de conocimiento en la clase de LM como L1, y por otro lado, hacemos más sensibles a las demandas lingüísticas el resto de las clases."

En esencia, el «currículo integrado» debe formar parte inseparable del PLC, pues de ese modo se puede superar el concepto de lengua-asignatura descontextualizado, a la par que se logra que el estudiante de una LE no la perciba como algo aislado dentro del Proyecto Educativo de Centro, como algo que no cumple ninguna función en su vida, que no le resulta práctico y de utilidad. Se trata justo de todo lo contrario; a saber: de que al estudiar los contenidos de las ANLs en L2, el alumno pueda profundizar en el conocimiento de si mismo, pueda usar la L2 para resolver aspectos prácticos de su vida, pueda mantener un contacto más fructífero con sus compañeros y con su entorno físico y social. Por ello, la aplicación del «currículo integrado» en el aula es garantía de éxito escolar para el estudiante, pues, tal como nos señala M. Met, (1994, p. 159), "en contextos de inmersión es posible desarrollar las destrezas en comunicación lingüística, al mismo tiempo que se acelera el conocimiento de los contenidos curriculares". Y dicho éxito solo será posible si la escuela atiende de forma efectiva y desde el PLC las demandas lingüísticas de los alumnos/as. Demandas que han de ser satisfechas desde la aplicación del «currículo integrado» como instrumento de minuciosa planificación de todas las actividades de enseñanza de lenguas promovidas desde la Sección Bilingüe. Una planificación que demanda un alto grado de coordinación en el diseño de las estrategias de aprendizaje de las lenguas a través de contenidos que surjan tanto en el marco general del PLC como en el marco específico del desarrollo del «currículo integrado».

Y para poder hacer realidad esta convivencia entre el PLC y el «currículo integrado» se precisa de un profesorado de lenguas bien formado, con independencia de que trabaje en el aula con la L1 o la L2. Este profesorado es el que debe realizar la labor de coordinación de lo que se enseña en las ALs y ANLs del currículo; es decir, debe de lograr el modo de integrar las lenguas y los contenidos, partiendo de una misma tarea y practicando los diversos géneros discursivos en distintos niveles de competencia comunicativa. Este profesorado es el que tiene la iniciativa, el que ha recibido de la Administración Educativa el encargo de desarrollar modelos autónomos de educación lingüística, dejando a un lado la tutela que hasta ahora ejercían las autoridades educativas sobre las 
propuestas de los Centros. Son, por tanto, los profesores los primeros interesados en entender que el «currículo integrado» es una herramienta que busca desarrollar la competencia plurilingüe y pluricultural de los alumnos y que apuesta por fomentar la tolerancia lingüística como condición primaria para sostener la diversidad lingüística en Europa. En definitiva, lo que se pretende en la educación bilingüe es preparar a los alumnos para construir una sociedad mejor, por medio de una educación de calidad. Un propósito que, en palabras de J. Gimeno Sacristán, (2002, p. 30) ha de parecernos utópico, en el mejor sentido del término, pues "si bien la educación se nutre de la cultura conquistada y es por eso reproductiva, encuentra su sentido más moderno como proyecto, en tanto que tiene capacidad de hacer aflorar hombres y mujeres, mejor vida; es decir, que encuentra su justificación en trascender el presente y todo lo que nos viene dado, sin utopía no hay educación". Una educación que, en el caso del modelo bilingüe se vertebra desde el «currículo integrado», el cual comparte con el PLC la premisa básica de que la adquisición de las lenguas no es un saber escolar, sino que es una competencia humana. Competencia que nada tiene que ver con el saber teórico, pues la aptitud de cada sujeto para aprender las lenguas es un don natural que está a disposición de todas las personas y que jamás se puede imponer a nadie.

Otro de los motivos por los cuales no podemos desligar al «currículo integrado» del PLC procede del hecho de que ambos recursos pedagógicos convergen mucho más que divergen. De entrada podemos afirmar que la singularidad del modelo de educación bilingüe, impulsado desde el desarrollo del «currículo integrado»; a saber; aprendizaje intensivo de diversos idiomas y el estudio de la cultura contenido en cada uno de ellos, no es otra cosa que la concreción de los objetivos generales planteados en el PLC. Por ello, estas dos realidades aquí aludidas caminan en la misma dirección, pues todas las lenguas que se usan en el Centro escolar pretenden incrementar la competencia comunicativa de los alumnos/as, entendida esta como una competencia global y plurilingüe propia de todos los individuos. Es este un modelo de adquisición de la lengua que se sustenta en el aprendizaje de conocimientos y en el desarrollo de destrezas, y que integra las actitudes, los valores culturales y cívicos, además de la competencia pluricultural. Esta concepción de la lengua está en los fundamentos de la metodología CLIL o AICLE propia de la educación bilingüe. Un enfoque del estudio de lenguas que pone su acento en el valor comunicativo de las mismas, las cuales deben ser asumidas desde las capacidades lingüísticas y de reflexión de cada sujeto. Este valor comunicativo se extiende a todas las lenguas del currículum escolar, las cuales están en contacto permanente, dando lugar a las correspondientes transferencias. Ello supone que las estrategias y las funciones comunicativas que se impulsan desde la L2 tienen un valor derivado y sirven para un uso más consciente de la L1. Tanto desde la L1 como desde la L2 se pueden impulsar la expresión oral y escrita, por medio de la realización de actividades de le lengua. Esta influencia mutua es positiva y contribuye a configurar el marco de 
las enseñanzas del Centro, con un referente común para todas las lenguas. En resumen, se trata de que esta convivencia entre el PLC y el «currículo integrado» potencie la implantación en los IES bilingües de llamado bilingüismo aditivo, el cual, en palabras de A. Huguet et alii (1994, p. 18), "aparece cuando los individuos incorporan una nueva lengua sin que la suya resulte perjudicada. Entonces la actitud ante las lenguas y comunidades resulta positiva y los aprendizajes de ambas se refuerzan mutuamente; así sucede en los programas de inmersión en los que un alumnado perteneciente a un grupo etnolingüístico de alto prestigio participa en ellos de una manera voluntaria, caso de los anglófonos de Canadá." Un enfoque del bilingüismo que, a diferencia del sustractivo, impulsa la distribución de las lenguas entre las diferentes áreas del currículo, de tal forma que cada materia del mismo se imparta en una de ellas, a la par que la lengua meta se usa como instrumento de comunicación y también para construir los aprendizajes de cada área en cuestión. En síntesis, este maridaje entre el PLC y el «currículo integrado» promueve la reflexión metalingüística y afianza un modelo de análisis interlingüístico, el cual posibilita una gestión plurilingüe del currículo.

\section{4. ¿EN QÚE MEDIDA EL «LENGUAJE INTEGRADO» CONFORMA EL SOPORTE TEÓRICO DEL «CURRICULO INTEGRADO».}

Una vez encontrado el acomodo del «currículo integrado» entre las líneas maestras del PLC, nos parece oportuno ofrecer al lector lo que, a nuestro entender, constituye su antecedente inmediato; a saber: «el lenguaje integrado» (whole language). Nos parece importante que el profesorado de las ALs y ANLs de las Secciones Bilingües de los IES cuente con una explicación coherente en relación con las posibles raíces del "currículo integrado», pues de este modo alcanzará a comprender con más facilidad el alcance educativo y el valor pedagógico de la integración de las lenguas y contenidos como propuesta educativa básica del modelo bilingüe. En este cometido hemos de comenzar afirmando que, de entrada, no es fácil encontrar una definición del concepto de «lenguaje integrado» que sea asumida por todos, pues no existe un acuerdo entre los expertos sobre esta cuestión. Para empezar podemos señalar que el «lenguaje integrado» se refiere, en esencia, a la naturaleza del lenguaje, a su papel en el currículo y a las características que han de definir las actividades de quienes enseñan y aprenden en la escuela. Esta naturaleza del lenguaje une a maestros y estudiantes, como comunidad democrática de aprendizaje en la cual el lenguaje es el vínculo común. Por ello la finalidad primaria del «lenguaje integrado» - compartida en esencia por el «currículo integrado» - consiste en incrementar en los alumnos su capacidad de comprensión de las lenguas y su fluidez de expresión al usarlas. El movimiento pedagógico del «lenguaje integrado» se sustenta en el pensamiento y en la filosofía de "creer en lo que se aprende", en mostrar una actitud positiva hacia el aprendizaje de los contenidos del currículo a través de las lenguas. 
Tal como antes indicamos, y a falta de una definición del «lenguaje integrado» que podamos considerar consensuada, nos quedamos con la que nos proporciona $\mathrm{J}$. M. Newman, (1991, p. 74), el cual señala que "el término lenguaje integrado se refiere a una constelación completa de creencias sobre los que aprenden y sobre el contexto social del aprendizaje. El lenguaje integrado no especifica una forma concreta de instrucción, ni tampoco recomienda ningún tipo especial de material o de libros". De estas palabras deducimos que el «lenguaje integrado» es una programa instruccional que se sustenta en el intercambio de las creencias de los maestros, su conocimiento de las estrategias instruccionales y en lo que ellos mismos aprenden de sus propios estudiantes. Es un programa que no impone ni dictamina lo que se tiene que hacer, sino que pretende cambiar el punto de vista de estudiantes y profesores en relación con el aprendizaje de lenguas. Según ello, el docente que adopta la perspectiva del «lenguaje integrado» busca que sus estudiantes sean aprendices activos, capaces de tomar el control de su propio aprendizaje. Por ello, tal como nos precisa P. Lacasa, (1995, p. 5), "el lenguaje integrado se presenta, ante todo, como una alternativa a aquellos programas que acercan a los niños al universo de lo impreso prescindiendo, al menos en gran medida, de que la lectura y la escritura son algo más que un conjunto de actividades relacionadas con el hecho de descifrar un determinado código.”

Sin embargo, aquí no terminan lo que nosotros entendemos son los antecedentes del «currículo integrado». Otra de las fuentes en la que se inspira dicho currículo procede del hecho de que para el «lenguaje integrado» el lenguaje hablado es el principio esencial del aprendizaje de las lenguas. Por ello para los partidarios de este movimiento innovador se hace preciso observar la forma en que los niños aprenden el lenguaje, pues esta será una excelente fuente de inspiración en las aulas de cara a diseñar actividades que aproximen a los niños a la lectoescritura. Este es un claro precedente de la educación bilingüe; a saber: que la lengua se aprende con el uso, con la práctica significativa de la misma y no con su estudio teórico. Aludimos a un aprendizaje significativo de la lengua como una seña de identidad del «lenguaje integrado», el cual, en palabras de Beatriz Martín, (1995, p. 21), "es un movimiento pedagógico que se presenta como un programa alternativo de alfabetización. Su postulado central es que el lenguaje se debe enseñar de forma global; es decir, con sus sistemas semánticos, sintácticos, lingüísticos y grafo-fonéticos intactos, y en situaciones significativas, en las que el uso de la lengua tenga un propósito o una meta determinada." Un modo de entender el lenguaje que tiene bien presente el contexto situacional en el que se usa y el conocimiento previo de cada alumno, activado en dicho contexto. Dicho de otro modo, el «lenguaje integrado» intenta desarrollar las actividades lingüísticas del aprendiz aprovechando las relaciones naturales que existen entre todos los componentes de la lengua. Este posicionamiento es asumido por el modelo lingüístico que se desprende del «currículo integrado», en el cual todos los 
procesos y actos relacionados con el uso y aprendizaje de las lenguas están interconectados.

Son, por tanto, las situaciones significativas las que otorgan pleno sentido a los actos de habla, sean estos producto de la aplicación del modelo pedagógico que propone el «lenguaje integrado» o bien resulten del desarrollo del «currículo integrado». En ambos casos la función principal de todo proceso lingüístico es la construcción de significados, los cuales deben ser transmitidos del que habla al que escucha y viceversa. De lo que se trata es de proporcionar interacciones significativas entre los hablantes, por medio de un uso funcional de la lengua en experiencias cotidianas reales. Esta vinculación del lenguaje a su uso en situaciones significativas contribuye a reforzar la idea de que su enseñanza ha de ser holística, como un todo no fragmentado. Por ello los distintos sistemas del lenguaje: fonología en lo oral, ortografía en lo escrito, morfología, sintaxis, semántica y pragmática están presentes simultáneamente en todo uso del lenguaje.

Pero esto no es todo, los partidarios del «lenguaje integrado» en su afán por fundamentar correctamente las bases teóricas de este movimiento recurren a John Dewy $(1939,1943)$ y retoman de este autor su concepto de «currículo integrado», el cual nos precisa que en la vida real del niño el conocimiento no se estructura en compartimentos estanco, sino que las materias del currículo deben presentarse como un todo integrado. Por ello, el lenguaje oral, la lectura y la escritura tienen que ser usados sobre la certeza de que han de permitir al niño dar cuenta de sus experiencias y aprender de las experiencias ajenas. En esta misma línea abunda $\mathrm{H}$. Taba $(1952,1960)$, el cual en sus trabajos realizados sobre el «currículo integrado» en los 60 del pasado siglo, insiste en la necesidad de situar al niño más allá de las relaciones que puedan establecerse entre las distintas materias del currículo, para de verdad integrar actividades y valores en el desarrollo del conocimiento. Un modelo de currículo, en el que a juicio de M Pujol, (1994b, p. 11), "la enseñanzaaprendizaje de la lengua se inscribe en un proyecto pedagógico integrado, con una serie de objetivos de aprendizaje y una secuencia didáctica compuesta por diferentes módulos, cada uno de ellos con una finalidad y un objetivo específico y bien definido. Cada uno de ellos contiene ejercicios relativos a cada una de las dimensiones discursivas en las que el trabajo integrado sobre los textos se alterna con un trabajo local sobre las unidades lingüísticas."

Y es este enfoque del «lenguaje integrado» el que se contempló en los Diseños Curriculares Base que dieron pie a la LOGSE en 1990. Una norma educativa en la que se incide en el enfoque constructivista de la enseñanza y se prima el papel activo de quien aprende. Por ello, en el DCB del MEC, (1989, p. 261), se afirma que "el lenguaje se convierte en un instrumento fundamental para construir una representación del mundo más o menos compartida, esencialmente comunicable, en un instrumento básico para la construcción del conocimiento, para la realización de aprendizajes y para el logro de una plena integración social y cultural." Ahora sí podemos afirmar que el influjo del «lenguaje integrado», como movimiento 
innovador en el ámbito de la enseñanza de lenguas, es más potente de lo que en principio podíamos pensar. Influjo que, en el caso del «currículo integrado» resulta obvio, pues ambos enfoques coinciden en asentar la enseñanza del lenguaje sobre situaciones significativas y dan gran importancia a los textos reales y a la construcción del conocimiento sobre la base ya adquirida por el niño previamente.

En suma, hemos explicitado una serie de analogías, gracias a las cuales el profesorado de las Secciones Bilingües puede contar con una explicación bien fundamentada sobre los orígenes de lo que hoy entendemos por «currículo integrado»

\section{5- DE LA TEORÍA A LA PRÁCTICA: UNA SECUENCIACIÓN DE CONTENIDOS DE MATEMÁTICAS PARA $1^{\circ}$ DE ESO BILINGÜE.}

En el interés de aportar al lector una aplicación práctica de lo que nosotros entendemos por «currículo integrado», que pueda servir de pauta a la hora de trabajar de manera conjunta los contenidos y las lenguas en las ANLs de los IES bilingües, pasamos a presentar una muestra de una secuenciación de contenidos del área de Matemáticas para $1^{\circ}$ de ESO. De todas las Unidades Didácticas que se incluyen en la Programación, seleccionamos aquellas que pueden ser especialmente ilustrativas.

A.- Objetivos Específicos Básicos del Área para $1^{\circ}$ de ESO bilingüe:

1.- Utilizar el conocimiento matemático para organizar, interpretar $\mathrm{e}$ interrelacionar diversas situaciones de la realidad.

2.- Comprender e interpretar distintas formas de expresión matemática, incorporándolas al lenguaje y a los modos de argumentación habituales, utilizando para ello la lengua española e inglesa, para lograr un aumento de los niveles de competencia lingüística de los alumnos.

3.- Afianzar en los alumnos/as los aspectos morfosintácticos, léxicos y gramaticales, así como conversacionales del inglés. Los alumnos han de usar tanto la lengua oral como la escrita en español e inglés, como forma de comunicación y vía de expresión personal en distintos ámbitos y en cualquier situación real.

4.- Reconocer y plantear situaciones en las que existan problemas susceptibles de ser formulados en términos matemáticos, utilizar diferentes estrategias para analizar los resultados utilizando recursos apropiados.

5.- Reflexionar sobre las propias estrategias utilizadas en las actividades matemáticas

6.- Incorporar hábitos y actitudes propios de la actividad matemática.

7.- Utilizar con soltura y sentido crítico los distintos recursos, con especial énfasis en los recursos tecnológicos (calculadora, programas informáticos, Internet, etc.) de tal forma que supongan una ayuda en el aprendizaje y en las 
aplicaciones instrumentales de las matemáticas, así como una ayuda para la comunicación con otras personas. Utilizar el inglés como medio de conocimiento de contenidos y para fomentar las actitudes de libertad y tolerancia, favoreciendo el intercambio de experiencias.

\section{B.- Propuesta metodológica:}

1.- Introducir de manera progresiva del "classroom language" en las relaciones entre profesor y alumno, y entre los alumnos.

2.- Utilización, una vez que se hayan asimilado los contenidos en español, de recursos como: fichas, programas informáticos, páginas web, etc. Cuya finalidad es:

a) Practicar con un amplio tipo de ejercicios sobre contenidos básicos, al mismo tiempo que se refuerza su aprendizaje.

b) Relacionar dichos contenidos en un contexto amplio que favorezca el uso de un vocabulario diverso y de las expresiones más usuales en inglés.

c) Procurar que las actividades contengan elementos motivadores para el alumno/a y que permitan su interrelación con sus compañeros (juegos, tests, representaciones gráficas, etc.)

3.- Tales actividades en inglés se realizan en forma de tareas y se desarrollan individualmente y en grupo. Se sigue un orden lógico en el desarrollo de la asignatura. Y se valora la expresión oral y escrita del alumno al realizarlas.

C.- The aims of this Programme will be:

1.- To improve the quality of learning and teaching in the classroom.

2.- To improve the quality of the school leadership.

3.- To raise the morale in the school overall.

4.- To raise appropriately the levels of teachers' expectations of their pupils.

5.- To increase pupils' self-esteem and sense of self-worth.

6.- To improve the quality of pupils' educational experiences.

7.- To improve pupils' employability.

8.- To foster continuity, coherence and progression in pupils' learning.

9.- To improve pupils attendance rates.

10.- To reduce teachers absenteeism and to improve standards of behaviour.

D.- The Teaching of English and Mathematics:

1.- We know that all the skills involved in the subjects of English and mathematics are important, and need to be developed in a coherent way. To improve literacy and numeracy skills, work therefore needs to focus on the 
whole subjects of English and mathematics, rather than solely on reading and number.

2.- The teaching of broader skills of English and mathematics, that is, helping children to become fluent in the use of written and spoken English, able to suit their language to different audiences, contexts and purposes, and to become confident and able readers for both information and pleasure, and confident and competent written and oral mathematicians.

3.- For teachers to teach effectively, they need to have a sound knowledge of how, and how successfully, their pupils are learning, and to be able to use their professional judgement and skills to intervene where learning has not happened. Close and accurate monitoring of success in learning, with each child and as each topic is taught, is vital to ensure progress. This is true of any subject, but is particularly important in mathematics, where learning builds on what gone before.

4.- Measures to improve standards in literacy and numeracy, therefore, should aim, not to impose any additional border on teachers and schools, but to help them improve de quality of the work they already do. The focus will therefore be on helping teachers improve and make more use of their diagnostic skills, and so help minimise testing to that enough information to help monitor progress.

E.- $\underline{\text { Secuencias de contenidos del área de Matemáticas para } 1^{\circ} \text { ESO bilingüe: }}$

Bloque $1^{\circ}$ de Contenidos: Números y Medidas

Contenido de la Unidad $1^{\text {a: }}$ Los números naturales

\begin{tabular}{|c|c|c|c|}
\hline CONCEPTOS & PROCEDIMIENTOS & ACTITUDES & CONTENTS, Un. $1^{a}$ \\
\hline $\begin{array}{l}\text { * Números naturales. } \\
\text { Funciones de conteo. } \\
\text { * Números naturales } \\
\text { como ordinales. } \\
\text { Ordenación de los } \\
\text { elementos de un } \\
\text { conjunto. } \\
\text { * Códigos numéricos } \\
\text { y alfanuméricos } \\
\text { con números } \\
\text { naturales. } \\
\text { * Función de los } \\
\text { números naturales } \\
\text { para estimar / } \\
\text { aproximar medidas. }\end{array}$ & $\begin{array}{l}\text { * Elaboración de estrategias } \\
\text { personales de cálculo mental. } \\
\text { * Utilización de diagramas en } \\
\text { árbol para el conteo. } \\
\text { * Utilización de los números } \\
\text { naturales para codificar infor- } \\
\text { maciones de carácter numérico } \\
\text { o alfanumérico. } \\
\text { * Estimación previa de } \\
\text { resultados } \\
\text { y aproximación de medidas } \\
\text { con } \\
\text { números naturales. } \\
\text { * Lectura y escritura de números } \\
\text { comprendidos entre las seis y }\end{array}$ & $\begin{array}{l}\text { * Valoración de la } \\
\text { aplicación de las } \\
\text { propiedades de } \\
\text { conjuntos } \\
\text { numéricos } \\
\text { para simplificar la } \\
\text { operatoria con } \\
\text { ellos. } \\
\text { * Confianza en las } \\
\text { la propia capacidad } \\
\text { para realizar } \\
\text { estimaciones y } \\
\text { cálculos con toda } \\
\text { clase de números. } \\
\text { * Curiosidad e } \\
\text { interés por las } \\
\text { investigaciones y }\end{array}$ & $\begin{array}{l}\text { *"Classroom language": } \\
\text { - Vocabulary and } \\
\text { usual sentences. } \\
\text { * Examples/Workouts/ } \\
\text { Quiz: } \\
\text { - Cardinal numbers: } \\
\text { * Revision ands } \\
\text { sequences. } \\
\text { * Reading and } \\
\text { writing numbers. } \\
\text { * Composition and } \\
\text { comparison of } \\
\text { numbers. } \\
\text { * Bigger and } \\
\text { smaller. }\end{array}$ \\
\hline
\end{tabular}




\begin{tabular}{|c|c|c|c|}
\hline $\begin{array}{l}\text { * El Sistema } \\
\text { Numérico Decimal, } \\
\text { Los grandes } \\
\text { órdenes } \\
\text { de unidades: millón, } \\
\text { millardos, billones. } \\
\text { * Recta numérica } \\
\text { Identificación de } \\
\text { puntos con números } \\
\text { naturales. } \\
\text { * Reglas de uso de la } \\
\text { calculadora.Función } \\
\text { de memoria. }\end{array}$ & $\begin{array}{l}\text { * Utilización de la calculadora } \\
\text { para mejorar el cálculo mental, } \\
\text { la estimación y los conceptos } \\
\text { de operaciones. } \\
\text { * Obtención de cocientes y restos } \\
\text { de divisiones por medio de la } \\
\text { calculadora. } \\
\text { * Aplicación diestra de los } \\
\text { algoritmos para operaciones } \\
\text { con números naturales. } \\
\text { * Resolución de expresiones con } \\
\text { operaciones combinadas de } \\
\text { números naturales. } \\
\text { * Identificación de operaciones } \\
\text { aritméticas oportunas en } \\
\text { situaciones problemáticas. } \\
\text { * Justificación y revisión crítica } \\
\text { de las soluciones a los } \\
\text { problemas. }\end{array}$ & $\begin{array}{l}\text { por la resolución } \\
\text { de los problemas } \\
\text { numéricos. } \\
\text { * Interés por las } \\
\text { estrategias, modos } \\
\text { de hacer y solución } \\
\text { a los problemas } \\
\text { numéricos distintos } \\
\text { a los propios. } \\
\text { * Sensibilidad y } \\
\text { gusto por la } \\
\text { presentación } \\
\text { ordenada y clara } \\
\text { del proceso } \\
\text { seguido } \\
\text { (expresando lo que } \\
\text { se hace y por qué } \\
\text { se hace) y de los } \\
\text { resultados en } \\
\text { cálculo y } \\
\text { problemas } \\
\text { numéricos. } \\
\text { * Confianza en las } \\
\text { propias } \\
\text { capacidades } \\
\text { para afrontar y } \\
\text { resolver problemas } \\
\text { numéricos. } \\
\text { * Disposición } \\
\text { favorable a revisión } \\
\text { y posible mejora } \\
\text { del resultado y } \\
\text { las soluciones de } \\
\text { los problemas } \\
\text { numéricos. }\end{array}$ & $\begin{array}{l}\text { - Ordinal numbers: } \\
\text { * Comparison and } \\
\text { order. } \\
\text { * Behind. In front } \\
\text { *The symbols: < and } \\
\text { >. } \\
\text {-Addition and subtraction } \\
\text { - Multiplication and } \\
\text { Division. } \\
\text { - Order of calculation. } \\
\text { - Numbers Pattern: } \\
\text { * Exploring } \\
\text { number } \\
\quad \text { patterns. } \\
\text { in Number patterns } \\
\text { * Number patterns, } \\
\quad \text { rules and finding } \\
\text { the nth term. } \\
\text { - Properties of numbers } \\
\text { and sequences: } \\
\text { * Recognise and extend } \\
\text { number sequences, such } \\
\text { as the sequence of square } \\
\text { numbers, or the sequence } \\
\text { of triangular numbers } \\
\text { 1,3,6,10,15... } \\
\text { * Make general } \\
\text { statements about odd or } \\
\text { even numbers, including } \\
\text { the outcome of products } \\
\text { * Recognise multiples of } \\
\text { to } 10 \text { x 10. Know and } \\
\text { apply simple tests of } \\
\text { divisibility. Find simple } \\
\text { common multiples. }\end{array}$ \\
\hline
\end{tabular}

\begin{tabular}{|c|c|c|c|}
\hline \multicolumn{4}{|c|}{$\begin{array}{l}\text { Bloque } 1^{0} \text { de Contenidos: Nímeros y Medidas } \\
\text { Contenidos de la Unidad } 2^{\text {a }} \text { : Potencias y raíces }\end{array}$} \\
\hline CONCEPTOS & PROCEDIMIENTOS & ACTITUDES & CONTENTS, Un. $2^{\mathrm{a}}$ \\
\hline $\begin{array}{l}\text { *El cuadrado y el cubo } \\
\text {-Significado } \\
\text { geométrico. } \\
\text {-Cuadrados perfectos } \\
\text { * Potencias } \\
\text { de base y exponente } \\
\text { natural. } \\
\text { Expresión, } \\
\text { nomenclatura y } \\
\text { cálculo. }\end{array}$ & $\begin{array}{l}\text { * Cálculo de la superficie de } \\
\text { un cuadrado a partir de } \\
\text { lado. Expresión aritmética } \\
\text { en forma de ponencia. } \\
\text { *Cálculo del número de } \\
\text { unidades que contiene un } \\
\text { cubo de lado conocido. } \\
\text { Expresión aritmética en } \\
\text { forma de potencia. }\end{array}$ & $\begin{array}{l}\text { * Interés por la } \\
\text { exposición clara de } \\
\text { informaciones y de } \\
\text { cálculos numéricos, } \\
\text { así como por los } \\
\text { recursos que lo } \\
\text { facilitan. } \\
\text { * Valoración del } \\
\text { lenguaje } \\
\text { matemático como }\end{array}$ & $\begin{array}{l}\text { * Classroom language": } \\
\text { - Vocabulary and usual } \\
\text { sentences- } \\
\text { * Examples/workouts/ } \\
\text { quiz: } \\
\text { - Square and cube } \\
\text { numbers: } \\
\text { * Multiplying by } 10,100, \\
1000 \ldots \\
\text { * Dividing by } 10,100, \\
1000 \ldots\end{array}$ \\
\hline
\end{tabular}




\begin{tabular}{|c|c|c|c|}
\hline $\begin{array}{l}\text { * Potencias base } 10 \\
\text { * Operaciones con } \\
\text { potencias: } \\
\text { - Producto potencias } \\
\text { de misma base. } \\
\text { - Cociente potencias } \\
\text { de misma base. } \\
\text { - Potencia de una } \\
\text { potencia } \\
\text { * Raíz cuadra: } \\
\text { - Relación con el } \\
\text { cuadrado. } \\
\text { - Raíces exactas } \\
\text { y aproximadas }\end{array}$ & 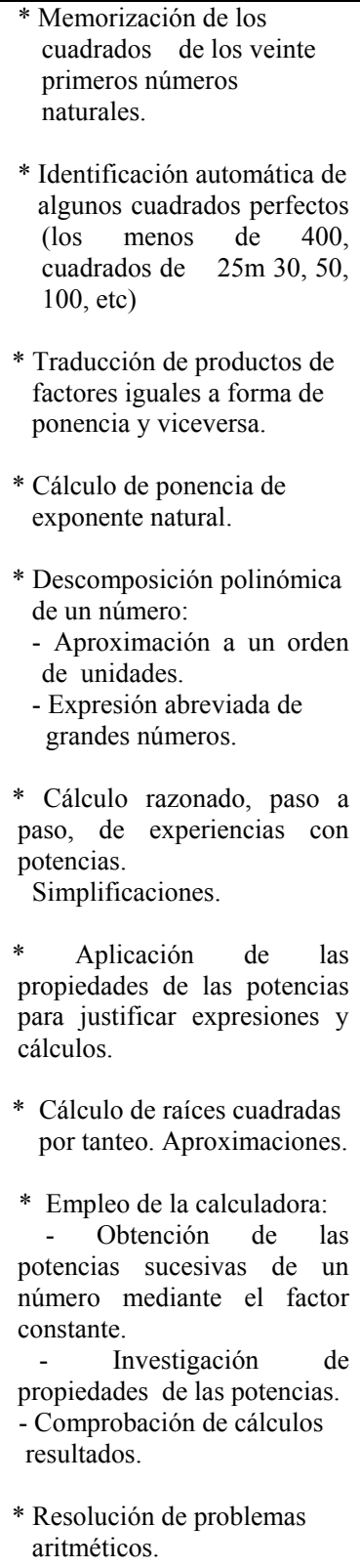 & $\begin{array}{l}\text { recurso que } \\
\text { facilita el cálculo. } \\
\text { * Interés por las } \\
\text { investigaciones de } \\
\text { las propiedades y } \\
\text { relaciones } \\
\text { numéricas. } \\
\text { * Interés por la } \\
\text { comprensión de los } \\
\text { procesos de cálculo. } \\
\text { * Interés por la } \\
\text { elaboración de } \\
\text { estrategias } \\
\text { personales de } \\
\text { cálculo mental y } \\
\text { escrito. }\end{array}$ & $\begin{array}{l}\text { *Index notation: power } \\
\text { *Approximating: } \\
\text { - Trial and improvement } \\
\text { * Place value, ordering } \\
\text { and } \\
\text { rounding: } \\
\text { - Multiply and divide } \\
\text { decimals mentally by } 10 \\
\text { or } 100 \text {, and integers } \\
\text { by } 1000 \text {, and explain the } \\
\text { effect. } \\
\text { - Use the vocabulary of } \\
\text { estimation and } \\
\text { approximation. } \\
\text { Consolidate rounding } \\
\text { an integer to the nearest } \\
10,1000 \text { or } 1000 . \\
\text { - Find the difference } \\
\text { between a positive an a } \\
\text { negative integer, or two } \\
\text { negative integers, in a } \\
\text { context such as } \\
\text { temperature or the } \\
\text { number line, and order a } \\
\text { set of positive and } \\
\text { negative integers. }\end{array}$ \\
\hline
\end{tabular}




\begin{tabular}{|c|c|c|c|}
\hline \multicolumn{4}{|c|}{$\begin{array}{c}\text { Bloque } \mathbf{1}^{\mathbf{0}} \text { de Contenidos: Números y Medidas. } \\
\text { Contenidos de la Unidad } 3^{\text {a: }} \text { Los números decimales } \\
\end{array}$} \\
\hline $\begin{array}{l}\text { CONCEPTOS } \\
\text { *Sistema Numérico } \\
\text { Decimal: } \\
\text {-Órdenes de las } \\
\text { unidades. } \\
\text {-Equivalencias entre } \\
\text { Los distintos } \\
\text { órdenes de } \\
\text { unidades. } \\
\text { * Tipos de números } \\
\text { decimales: exactos. } \\
\text { Periódicos, otros. } \\
\text { * Los decimales en la } \\
\text { recta numérica: } \\
\text {-Orden en el } \\
\text { conjunto de los } \\
\text { números decimales. } \\
\text { - Entre dos } \\
\text { decimales siempre } \\
\text { hay otro decimal. } \\
\text { * Operaciones con } \\
\text { números } \\
\text { decimales: } \\
\text { - Suma y resta. } \\
\text { - Producto y } \\
\text { cociente. } \\
\text {-Raíz cuadrada. } \\
\text { * Conocimiento de } \\
\text { las } \\
\text { particularidades de } \\
\text { la calculadora en el } \\
\text { manejo de los } \\
\text { números decimales. }\end{array}$ & 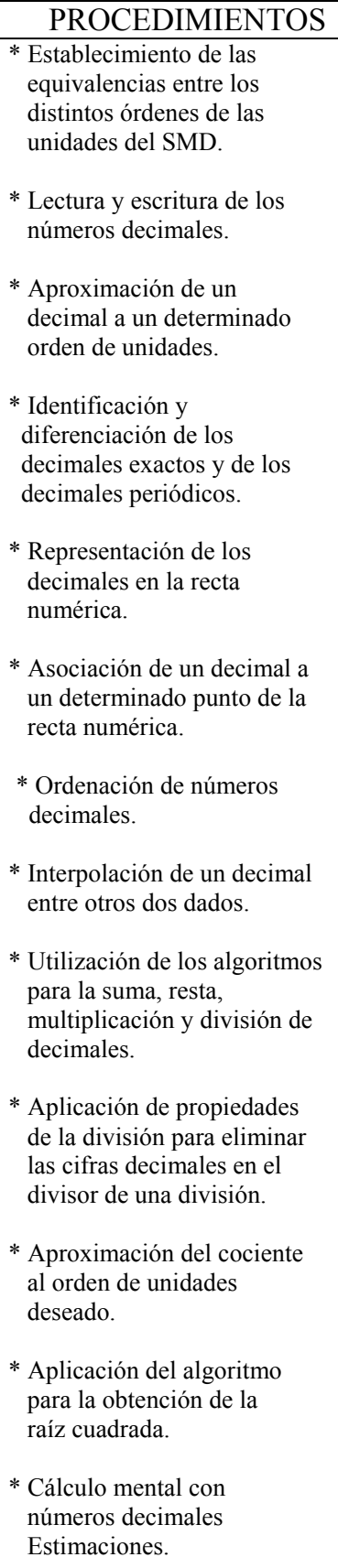 & $\begin{array}{l}\text { ACTITUDES } \\
\text { * Valoración de los } \\
\text { números decimales } \\
\text { como recurso para } \\
\text { transmitir } \\
\text { información } \\
\text { relativa al mundo } \\
\text { científico y a } \\
\text { situaciones } \\
\text { cotidianas. } \\
\text { * Valoración y } \\
\text { actitud crítica ante } \\
\text { la calculadora } \\
\text { como herramienta } \\
\text { para la operatoria } \\
\text { rápida. } \\
\text { * Interés por la } \\
\text { investigación de } \\
\text { las } \\
\text { propiedades y las } \\
\text { relaciones } \\
\text { numéricas. } \\
\text { * Interés por el } \\
\text { desarrollo de } \\
\text { estrategias } \\
\text { personales de } \\
\text { cálculo rápido. } \\
\text { * Tenacidad y } \\
\text { constancia ante } \\
\text { un problema }\end{array}$ & 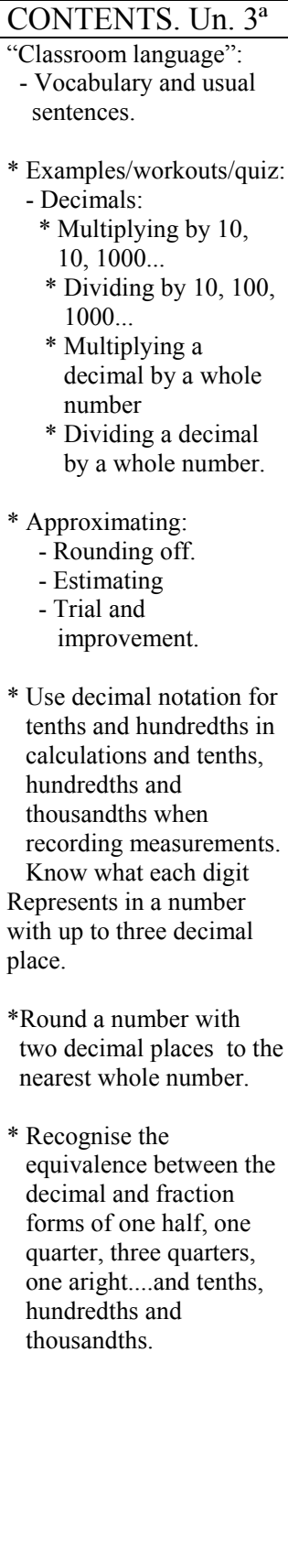 \\
\hline
\end{tabular}




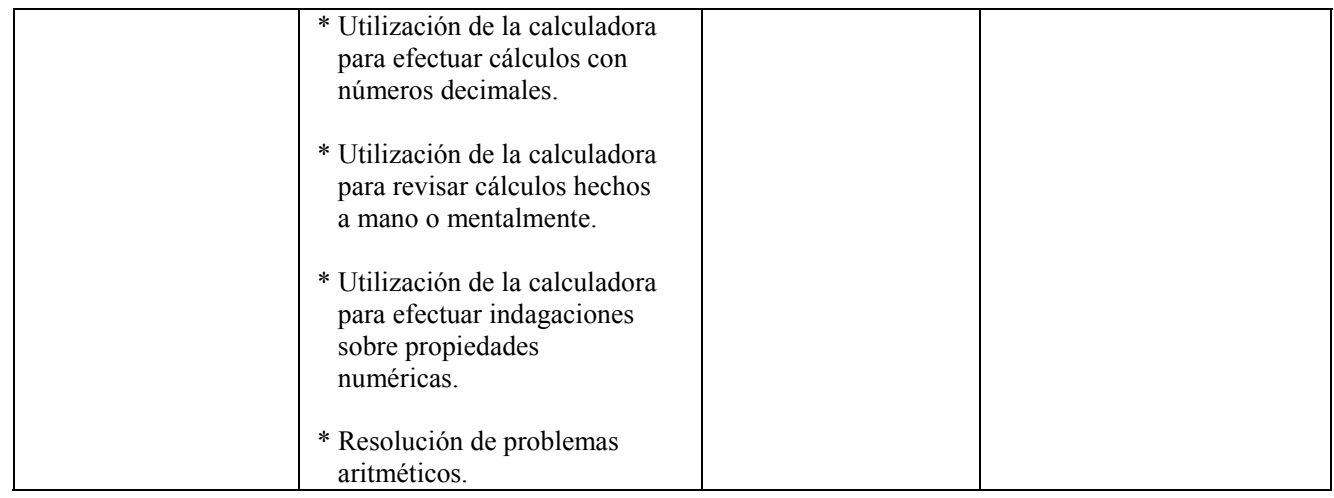

\begin{tabular}{|c|c|c|c|}
\hline \multicolumn{4}{|c|}{$\begin{array}{c}\text { Bloque } 1^{\circ} \text { de Contenidos: Números y Medidas } \\
\text { Contenidos de Unidad } 4^{\mathrm{a}} \text { : Las fracciones }\end{array}$} \\
\hline CONCEPTOS & PROCEDIMIENTOS & ACTITUDES & CONTENTS, Un. $4^{\mathrm{a}}$ \\
\hline $\begin{array}{l}\text { * Los significados de } \\
\text { una fracción: } \\
\text { - Fracción como } \\
\text { parte de unidad. } \\
\text { - Facción como } \\
\text { operador. } \\
\text { * Equivalencia de las } \\
\text { fracciones. } \\
\text { * Suma y restas de } \\
\text { fracciones: } \\
\text { - Propiedades de } \\
\text { suma y resta. } \\
\text { - Reglas para la } \\
\text { eliminación de los } \\
\text { paréntesis en las } \\
\text { expresiones } \\
\text { aritméticas con las } \\
\text { fracciones. } \\
\text { * Producto de las } \\
\text { fracciones: } \\
\text { - Fracción inversa } \\
\text { de una dada. } \\
\text { * Cociente de las } \\
\text { fracciones. }\end{array}$ & $\begin{array}{l}\text { * Representación de una } \\
\text { fracción como parte de unidad. } \\
\text { * Comparación de fracciones } \\
\text { con la unidad. } \\
\text { *Transformación de una } \\
\text { fracción en número decimal. } \\
\text { * Cálculo de fracción de un } \\
\text { número. } \\
\text { * Identificación y producto de } \\
\text { fracciones equivalentes. } \\
\text { * Transformación de un entero } \\
\text { en fracción. } \\
\text { *Simplificar fracciones } \\
\text { * Reducción de las fracciones a } \\
\text { común denominador. } \\
\text { * Comparación de fracciones: la } \\
\text { ordenación de un conjunto de } \\
\text { fracciones. } \\
\text { * Aplicación de los distintos } \\
\text { métodos y algoritmos para la } \\
\text { suma y resta de fracciones } \\
\text { previa reducción a común } \\
\text { denominador } \\
\text { * Resolución de expresiones }\end{array}$ & $\begin{array}{l}\text { *Valoración de los } \\
\text { números } \\
\text { fraccionarios como } \\
\text { soporte informativo } \\
\text { relativo al mundo } \\
\text { científico y a las } \\
\text { situaciones } \\
\text { cotidianas. } \\
\text { * Interés por la } \\
\text { investigación de } \\
\text { las propiedades y } \\
\text { las } \\
\text { relaciones } \\
\text { numéricas. } \\
\text { * Interés por el } \\
\text { desarrollo de } \\
\text { estrategias } \\
\text { personales } \\
\text { de cálculo rápido. } \\
\text { * Interés por la } \\
\text { exposición clara de } \\
\text { procesos y } \\
\text { resultados en los } \\
\text { cálculos con las } \\
\text { expresiones } \\
\text { aritméticas y en la } \\
\text { resolución de los } \\
\text { problemas. } \\
\text { * Tenacidad y } \\
\text { constancia ante un } \\
\text { problema. } \\
\text { Confianza en los } \\
\text { propios resultados. }\end{array}$ & $\begin{array}{l}\text { "Classroom language": } \\
\text {-Vocabulary and usual } \\
\text { sentences. } \\
\text { Examples/Workouts/Quiz: } \\
\text { * Fractions: } \\
\text { - Improper number and } \\
\text { improper fraction. } \\
\text { - Calculating fractional } \\
\text { parts of quantities } \\
\text { - Converting between } \\
\text { fractions and decimals } \\
\text { *Addition and } \\
\text { Subtraction of Fractions. } \\
\text { * Multiplication and } \\
\text { Division of Fractions. } \\
\text { * Use fraction as an } \\
\text { "operator" to find } \\
\text { fractions, including } \\
\text { tenths and hundredths, } \\
\text { of numbers or qualities } \\
\text { (e. g. } 5 / 8 \text { of } 32,7 / 10 \text { of } \\
40,9 / 100 \text { of } 400 \mathrm{~cm} \text { ) } \\
\text { * Order a mixed seed of } \\
\text { numbers or } \\
\text { measurements with up } \\
\text { to three decimal place. } \\
\text { * Round a number with } \\
\text { two decimal places to } \\
\text { the nearest tenth or to } \\
\text { the nearest to the whole }\end{array}$ \\
\hline
\end{tabular}




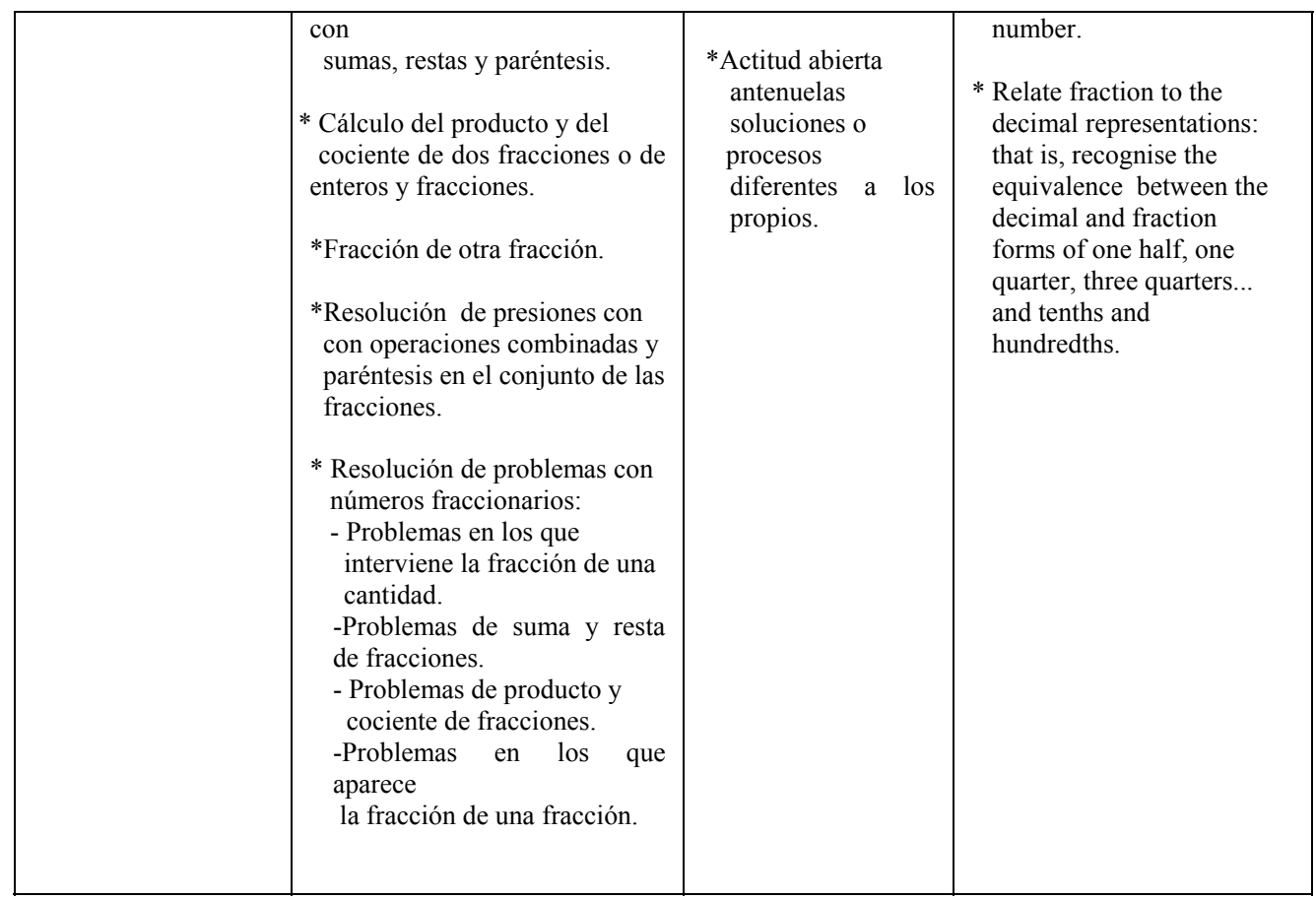

\begin{tabular}{|c|c|c|c|}
\hline \multicolumn{4}{|c|}{$\begin{array}{c}\text { Bloque } 1^{\circ} \text { de Contenidos: Números y Medidas } \\
\text { Contenidos de la Unidad } 5^{\mathrm{a}} \text { : Proporcionalidad }\end{array}$} \\
\hline CONCEPTOS & PROCEDIMIENTOS & ACTITUDES & CONTENTS, Un. $5^{\circ}$ \\
\hline $\begin{array}{l}\text { * La relación de } \\
\text { proporcionalidad } \\
\text { directa: } \\
\text { - Magnitudes } \\
\text { directamente } \\
\text { proporcionales. } \\
\text {-Tablas de valores } \\
\text { directamente } \\
\text { proporcionales. } \\
\text { * La relación de } \\
\text { proporcionalidad } \\
\text { inversa: } \\
\text { - Magnitudes } \\
\text { inversamente } \\
\text { proporcionales. } \\
\text { - Tablas de valores } \\
\text { inversamente } \\
\text { proporcionales. } \\
\text { * Fracciones } \\
\text { equivalentes en las } \\
\text { tablas de valores } \\
\text { directamente o }\end{array}$ & $\begin{array}{l}\text { * Identificación y diferenciación } \\
\text { de magnitudes directa e } \\
\text { inversamente proporcionales. } \\
\text { * Construcción de tablas de } \\
\text { valores directa o inversamente } \\
\text { proporcionales, a partir de un } \\
\text { par de valores } \\
\text { correspondientes. } \\
\text { * Investigación de relaciones } \\
\text { entre valores de una tabla de } \\
\text { proporcionalidad directa ( o } \\
\text { inversa) } \\
\text { * Construcción de fracciones } \\
\text { equivalentes con los pares de } \\
\text { valores correspondientes en } \\
\text { una tabla de } \\
\text { proporcionalidad directa (o } \\
\text { inversa) } \\
\text { * Aplicación de las propiedades } \\
\text { de las fracciones equivalentes } \\
\text { para completar pares de }\end{array}$ & $\begin{array}{l}\text { * Valoración de los } \\
\text { conceptos y } \\
\text { procedimientos } \\
\text { relativos a la } \\
\text { proporcionalidad } \\
\text { para su aplicación } \\
\text { práctica en la } \\
\text { resolución de las } \\
\text { situaciones } \\
\text { cotidianas. } \\
\text { * Interés por la } \\
\text { investigación de } \\
\text { las } \\
\text { relaciones y de las } \\
\text { propiedades } \\
\text { numéricas } \\
\text { * Valoración del } \\
\text { método de } \\
\text { reducción a la } \\
\text { unidad y de la } \\
\text { regla de tres como } \\
\text { recursos eficaces }\end{array}$ & $\begin{array}{l}\text { * Classroom language": } \\
\text { - Vocabulary and usual } \\
\text { sentences. } \\
\text { Examples/workouts/quiz } \\
\text { * Ratio and unitary method } \\
\text { - Equivalent ratios and } \\
\text { simplest form. } \\
\text { - Unitary ratios. } \\
\text { - Dividing in a given } \\
\text { ratios. } \\
\text {-Using ratios. } \\
\text {-Value for money. } \\
\text { *Percentages: } \\
\text { - Writing one number as a } \\
\text { percentage of another } \\
\text { * Calculating percentage } \\
\text { parts of quantities. } \\
\text { * Solve simple problems } \\
\text { involving ratio and } \\
\text { proportion. }\end{array}$ \\
\hline
\end{tabular}




\begin{tabular}{|c|c|c|c|}
\hline $\begin{array}{l}\text { inversamente } \\
\text { proporcionales. } \\
\text { * Problemas en la } \\
\text { proporcionalidad } \\
\text { directa } \\
\text { * Problemas en la } \\
\text { proporcionalidad } \\
\text { inversa. } \\
\text { * Porcentajes: } \\
\text { - Porcentaje como } \\
\text { relación de } \\
\text { proporcionalidad. } \\
\text {-El porcentaje como } \\
\text { fracción. }\end{array}$ & $\begin{array}{l}\text { valores en las tablas de } \\
\text { proporcionalidad directa ( o } \\
\text { inversa) } \\
\text { * Resolución de problemas de } \\
\text { proporcionalidad: } \\
\text { - Método de reducción a la } \\
\text { unidad. } \\
\text {-Regla de tres. } \\
\text { * Cálculo con porcentajes. } \\
\text { * Cálculo rápido de porcentajes } \\
\text { sencillos. } \\
\text { * Cálculo de porcentajes con la } \\
\text { calculadora. } \\
\text { * Resolución de problemas de } \\
\text { porcentajes: } \\
\text { - Problema directo. } \\
\text { Cálculo de la parte, } \\
\text { conocidos el total y el } \\
\text { \% inverso. } \\
\text { Problema } \\
\text { Cálculo } \\
\text { del total, conocidos \% y } \\
\text { parte. } \\
\text { Cálculo de porcentaje, } \\
\text { conocido el total y la } \\
\text { parte }\end{array}$ & $\begin{array}{l}\text { para resolver los } \\
\text { problemas. } \\
\text { * Tenacidad y } \\
\text { constancia en el } \\
\text { enfrentamiento a } \\
\text { un problema. } \\
\text { Confianza en las } \\
\text { Propias } \\
\text { capacidades y } \\
\text { recursos. } \\
\text { *Actitud crítica ante } \\
\text { la resolución de un } \\
\text { problema. } \\
\text { * Actitud abierta } \\
\text { para } \\
\text { aplicar lo que se } \\
\text { sabe a nuevas } \\
\text { situaciones. }\end{array}$ & $\begin{array}{l}\text { * Use decimal notation for } \\
\text { tenths and hundredths in } \\
\text { calculation, and tenths, } \\
\text { hundredths and } \\
\text { thousandths when } \\
\text { recording measurements } \\
\text { *Understand percentage as } \\
\text { the number of parts in } \\
\text { every } 100 . \\
\text { Express simple fraction } \\
\text { such one half, one } \\
\text { quarter, one third, two } \\
\text { third... } \\
\text { * Find simple percentages } \\
\text { of small whole number } \\
\text { quantities. }\end{array}$ \\
\hline
\end{tabular}

\section{Bloque $\mathbf{1}^{\circ}$ de Contenidos: Geometría}

Contenidos de la Unidad 6a: Longitudes y Áreas

\begin{tabular}{|c|c|c|c|}
\hline CONCEPTOS & PROCEDIMIENTOS & ACTITUDES & CONTENTS, Un. $6^{\mathrm{a}}$ \\
\hline $\begin{array}{l}\text { en los } \\
\text { los, } \\
\text { ss, } \\
\text { s, } \\
\text { gramos y } \\
\text { s regulares }\end{array}$ & $\begin{array}{l}\text { informaciones sobre medidas. } \\
\text { * Estimación como paso previo a } \\
\text { las diversas mediciones (para } \\
\text { tener una primera idea del } \\
\text { resultado y, después, poder } \\
\text { juzgar lo razonable de las } \\
\text { mismas) } \\
\text { * Medición de longitudes con } \\
\text { segmentos y de superficies con } \\
\text { cuadrículas. }\end{array}$ & $\begin{array}{l}\text { * Hábito de expresar } \\
\text { mediciones } \\
\text { indicando siempre } \\
\text { la } \\
\text { unidad de medida. } \\
\text { * Disposición } \\
\text { favorable para } \\
\text { estimar o calcular, } \\
\text { según convenga, de } \\
\text { medidas } \\
\text { superficie } \\
\text { * Reconocimiento del } \\
\text { teorema de } \\
\text { Pitágoras } \\
\text { como recurso }\end{array}$ & $\begin{array}{l}\text { “" "Classroom } \\
\text { language": } \\
- \text { Vocabulary and } \\
\text { usual } \\
\quad \text { sentences. } \\
\text { Examples/ } \\
\text { Workouts/Quiz } \\
\text { * Use of measure: } \\
\text { - Choosing appropriate } \\
\text { units. } \\
\text { - Perimeter and area } \\
\text { * Polygons: } \\
\text { - Perimeter and area of } \\
\text { polygon. } \\
\text { * Circumference and }\end{array}$ \\
\hline
\end{tabular}




\begin{tabular}{|c|c|c|c|}
\hline $\begin{array}{l}\text { Deducción de las } \\
\text { Fórmulas. } \\
\text { * Medias en polígonos } \\
\text { irregulares. } \\
\text { * Medias en un círculo } \\
\text { perímetro y área. } \\
\text { * Longitud de un arco } \\
\text { de circunferencia y la } \\
\text { superficie del sector } \\
\text { circular. } \\
\text { Deducción de las } \\
\text { fórmulas. }\end{array}$ & $\begin{array}{l}\text { - Por descomposición y } \\
\text { composición. } \\
\text { * Aplicación de la técnica de } \\
\text { triangulación para calcular la } \\
\text { superficie de polígonos } \\
\text { irregulares. } \\
\text { * Cálculo de: } \\
\text { - Área de un círculo. } \\
\text { - Longitud de circunferencia. } \\
\text { - Área de un sector circular. } \\
\text { * Resolución de problemas } \\
\text { geométricos relacionados con } \\
\text { el cálculo de áreas y } \\
\text { perímetros. }\end{array}$ & $\begin{array}{l}\text { valioso para la } \\
\text { obtención indirecta } \\
\text { de medidas. } \\
\text { * Cuidado en el uso } \\
\text { de diferentes } \\
\text { instrumentos de } \\
\text { medida. } \\
\text { * Revisión sistemática } \\
\text { del resultado de las } \\
\text { medidas obtenidas } \\
\text { mediante aplicación } \\
\text { de fórmulas, } \\
\text { aceptándolas o } \\
\text { rechazándolas según } \\
\text { se adecúen o no a } \\
\text { los } \\
\text { esperados. } \\
\text { *alores } \\
\text { * Flexibilidad para } \\
\text { enfrentarse a las } \\
\text { situaciones de } \\
\text { cálculo de áreas de } \\
\text { diferentes figuras } \\
\text { considerando varios } \\
\text { puntos de vista. } \\
\text { * Gusto por la } \\
\text { limpieza y precisión } \\
\text { en la construcción } \\
\text { de figuras } \\
\text { geométricas. } \\
\text { ante errores } \\
\text { geométricos en las } \\
\text { construcciones o } \\
\text { representaciones. } \\
\text { Capacidad de crítica } \\
\text { alien }\end{array}$ & $\begin{array}{l}\text { circle: } \\
\text { - Circumference and } \\
\text { are } \\
\text { area of circle. } \\
\text { - More problems an } \\
\text { area } \\
\text { and perimeter. } \\
\text { * Use, read and write } \\
\text { standard metric units } \\
\text { (km, } \\
\text { m, cm, mm, kg, } 1 \text { ml, } \\
\text { cl), } \\
\text { including } \\
\text { abbreviations } \\
\text { and relationships } \\
\text { between them. Convert } \\
\text { smaller to larger units } \\
\text { (e.g. } \\
\text { m to km, cm or mm to } \\
\text { m, g } \\
\text { to kg, ml to l) and vice } \\
\text { versa. } \\
\text { * Suggest suitable units } \\
\text { and } \\
\text { equipment measuring } \\
\text { to estimate or measure } \\
\text { length, mass } \\
\text { capacity. } \\
\text { Record estimates and } \\
\text { readings from scales to } \\
\text { a suitable degree of } \\
\text { accuracy. } \\
\text { * Calculate de perimeter } \\
\text { and area of simple } \\
\text { compound shapes that } \\
\text { can be split into } \\
\text { rectangles. } \\
\text { tound the } \\
\text { and }\end{array}$ \\
\hline
\end{tabular}

\section{6.- CONSIDERACIONES FINALES}

A lo largo de estas páginas hemos querido dejar constancia de que sí es posible realizar una aproximación al PLC desde un enfoque plurilingüe. Acercamiento que se concreta en el hecho de que el «currículo integrado» y el PLC son realidades complementarias, pues ambas comparten elementos esenciales capaces de aglutinar la planificación y los procesos de enseñanza-aprendizaje de las lenguas en el Centro escolar en torno a un currículum común. Esta convivencia positiva es la que 
se promueve en nuestras aulas de educación bilingüe una serie de cambios tanto en la organización de las mismas como en la utilización de los recursos didácticos necesarios.

Cambios que nos llevan a organizar las clases de tal manera que todos los aprendices puedan utilizar la lengua, al mismo tiempo que la estructura de dicha clase potencia los intercambios lingüísticos entre iguales. Modificaciones que son también metodológicas, con el fin de asegurarnos que desde cualquier área del currículum se atiende al aprendizaje de la L1 y L2, tanto en lo que afecta a la expresión oral como escrita. Unos cambios que solo han de ser posibles, tal como señala F. Ramos, (2007, ibídem, p. 9), "si se cuenta con profesionales cualificados que animen la preparación lingüística adecuada, junto al conocimiento de técnicas y estrategias específicas para la enseñanza de idiomas y contenidos. Estos son requisitos imprescindibles para que los alumnos reciban una instrucción estimulante que les ayude a progresar en la lectoescritura en dos idiomas." En todo caso, hablamos de un modo de proceder que reporta beneficios tanto para la L1 en particular y para los procesos cognitivos que sustentan en el trabajo escolar, como para los mecanismos discursivos y lingüísticos que sirven al pensamiento y a la comunicación, a través de cada una de las lenguas del currículo.

Además, este hermanamiento entre el PLC y el «currículo integrado» ha de facilitar la elaboración de programas integrados en la enseñanza de las lenguas, lo que implica contar con una toma de decisiones conjunta en el Equipo Docente, una elección de la adecuada metodología, del modelo de evaluación y de los recursos. Todo ello con el fin de propiciar la transferencia de los aprendizajes lingüísticos. En definitiva, podemos afirmar que entre las distintas lenguas que se hablan en el Centro, más allá de las diferencias de código, hay todo un conjunto de aprendizajes comunes relacionados con la competencia pragmática, la competencia textual, la construcción de conceptos sobre el funcionamiento de la lengua o sobre el desarrollo de actitudes positivas de tipo lingüístico. $\mathrm{Y}$ a través de este enfoque integrador de las lenguas lograremos que nuestros alumnos comprendan el mundo de los demás por contraste a cómo entienden el a suyo, pues tal como sostiene J. A. Tusón Valls, (1989: 136), “ una lengua, del millar de lenguas que existen en el mundo, es el instrumento simbólico mediante el cual organizamos nuestro entorno (...), las lenguas se convierten en instrumentos de comunicación humana y nos permiten transmitirnos el mundo de fuera y el mundo de dentro, con restricciones claro está, porque cada uno de nosotros es diferente y nuestras percepciones del mundo son matizadas."

$\mathrm{Y}$ es justo este valor comunicativo de las lenguas el que hemos querido subrayar en nuestra exposición. Esta capacidad del hablante para hacerse entender a través de su propia LM o por medio del uso de las LE se potencia en el medio escolar a través de la secuenciación de contenidos didácticos por nosotros presentada en forma de secuencia. Por medio de ellas hemos impulsado una iniciativa propia de los IES bilingües; a saber: la enseñanza de contenidos 
curriculares a través de la L2. Una enseñanza que viene respaldada por una adecuada programación didáctica, en la que han colaborado de forma activa todos los docentes.

En síntesis, lo que pretendemos es impulsar un modelo de enseñanza de lenguas en el que caben todas las sugerencias del profesorado en pro de un aprendizaje significativo de los contenidos, a través de las distintas lenguas del currículum como instrumentos vehiculares. De todo ello se deduce que el domino de las lenguas ha de ser una prioridad para nuestros alumnos de la ESO, ya que gracias a dicho dominio se abrirán sus mentes a nuevos conocimientos y contarán con recursos y estrategias para comprender y asumir todos los avances tecnológicos que se derivan de esta nueva sociedad del conocimiento.

\section{REFERENCIAS BIBLIOGRÁFICAS}

BAJTIN, M. (1929): Marxismo y filosofia del lenguaje. Madrid. Alianza.

BAJTIN, M. (1984): Estética de la creación verbal. Paris. Gallimard

BERGERON, B. S. (1990): "What does the term Whole Language mean? Constructing a definition from the literature", in Journal of Reading Behavior, XXII (4): 301-329.

BAKER, C. (1992): Acttitudes and Language. Clevelon. Multilingual Matters.

BERNAUS, Mercé (2004): "Un nuevo paradigma en la didáctica de las lenguas", en Revista Electrónica Internacional, 11: 3-13.

CEJAS MARTÍNEZ, M. (2000): "La educación basada en competencias: metodología que se propone en la Educación Superior y que busca estrechar la brecha entre el sector educativo y el productivo", en Bulletins del'Observatori Bolonia, 20: 17-26. Universidad Pompeu Fabra.

CEP de Jaén. Consejería de Educación (2011): El Proyecto Lingüistico de Centro. En web: www.cepjaen.es/vandelvira/index. Fecha consulta: 26.7.11

CONSEJERÍA DE EDUCACIÓN. Dirección General de Ordenación y Evaluación Educativa (2005): ¿Cómo elaborar el currículo integrado de lenguas y áreas no Lingüisticas? Aplicaciones didácticas. Sevilla.

CONSEJERÍA DE EDUCACIÓN. Dirección General de Ordenación y Evaluación Educativa (2007): Informe sobre las Pruebas de Diagnóstico. Sevilla.

CUMMINS, J. (1979): "Linguistic interdependence and the educational development of bilingual children", in Review of Educational Research, 49 (2): 222-251.

DEWEY, J. (1938): Experience in education. New York. Collier.

DEWEY, J. (1943): The child and curriculum, and the school and society. Chicago. University of Chicago Press.

GALERA NOGUERA, E. y MOLINA, J. L. (1998): "Procedimientos y estrategias de la enseñanza-aprendizaje de la Gramática", en Lenguaje y Textos, 16: 145154.

GIMENO SACRISTÁN, S. (2002): “La educación que tenemos, la educación que 
queremos”, en F. Imbernón, (coord), La educación del siglo XXI. Los retos del futuro inmediato. Barcelona. Graó.

GOODMAN, Y. M. y K. S. GOODMAN, (1990): "Vygotsky in a whole language perspective", in L. C. Moll (ed), Vigotsky and Education. Cambridge. Cambridge University Press.

GÓMEZ ALEMANY, I. (2000): "Bases teóricas de una propuesta didáctica para reforzar la comunicación en el aula", en J. Jorba, I. Gómez, A. Prats, (eds), Hablar y escribir para aprender. Madrid, Síntesis.

GONZÁlEZ VIDAL, A. y ARCOS, D. (2007): "Plan de Mejora de la Competencia Lingüística. Elaboración del Proyecto Lingüístico de Centro" en Avances en Supervisión Educativa, 7, www.adide.org/revista/index

GONZÁLEZ RIAÑO, J. A. (1998): El Proyecto Lingüístico de Centro en programación del aprendizaje lingüístico. Cap. III: 108-119, Servicio de Publicaciones. Universidad de Oviedo.

HUGUET, A, et alt, (1994): "Bilingüísmo y educación en la franja oriental de Aragón”, en Alacet, 6: 9-33.

LACASA, P. (1995): “Lenguaje integrado, ¿aprender a través de la práctica?”, en Comunicación, Lenguaje y Educación, 25: 5-6.

MAALOUF, A. (1999): Identidades asesinas. Madrid, Alianza Editorial.

MARTIN, B. (1995): "Lenguaje integrado: sus creencias sobre la alfabetización", en Comunicación Lenguaje y Educación, 25: 21-29.

MET, M. (1994): "Teaching content through a second lenguage", in F. Genesse (ed), Educating Second Language Children. New York. Cambridge University Press.

MINISTERIO DE EDUCACIÓN Y CIENCIA. (1989): Diseño Curricular Base, Madrid, Servicio de Publicaciones.

NEWMAN, J. M. (1991): "Whole language: a changed universe", in Contemporary Education, LXII (2): 76-81,

OJEDA ÁLVAREZ, D. (2008): "Integración de lenguas y contenidos en el marco de la enseñanza reglada", en I Jornadas sobre Lenguas, Currículo y alumnado emigrante", Bilbao, Universidad de Deusto, 71-82.

PUJOL, M. (1994b): "La pedagogía del texto: enseñanza y aprendizaje del producto final y del proceso de producción verbal", en Comunicación, Lenguaje y Educción, 23: 9.16

RAMOS, F. (2007): "Programas bilingües y formación del profesorado", en Revista Iberoamericana de Educación, 44: 133-146.

RUIZ BIKABDI, Uri. (1997): "Decisiones necesarias para la elaboración del Proyecto Lingüístico de Centro", Textos de Didáctica de Lengua y Literatura, 13: 9-24.

SAGATI ARRESTI, M. P. (2000): "La gestión del Proyecto Lingüístico de Centro desde una perspectiva ecológica", en Seminario de Lengua y Educación, 22: 185-193. 
TRUJILlO SÁEZ, Fernando, (2000): "Políticas de educación lingüística en Andalucía: competencia en comunicación lingüística en la escuela andaluza", en Policy papers, 12: 1-17.

TRUJILLO SÁEZ, Fernando, (2007): "Enseñar nuevas lenguas en la escuela: L1, L2, LE....NL.", en Revista de Educación, 343: 71-91.

SPADA, N. (1997): "From-focused instruction and second language adquisition", in Teaching, 30 73-87.

SPANOS, G. (1989): "On the integration of language and content instruction", in Annual Review of Applied Linguistic, 10: 227-240-

TABA, A. (1950): Elementary curriculum in intergroup relations, Washintong D. C. American Council on Education.

TABA, A. (1962): Curriculum development, New York, Harcourt, Brace and World

TUSÓN VALLS, J. A. (1989): El lujo del lenguaje, Barcelona, Paidós.

VEZ JEREMÍAS, J. M. (2008): La DEL: hoy para mañana", en Porta Linguarum, 1: 5-30. 